\title{
Issues in Adolescent and Young Adult Oncology in a Developing Country Like India
}

The WHO has defined adolescent and young adults (AYAs) population as individuals diagnosed with cancer between the age group of 15-39 years. The Teenage and Young Adults Cancer Foundation has defined the age group to be between 15 and 29 years. ${ }^{[1]}$ The interest in AYA oncology arose when in the mid-90s, Bleyer observed that adolescent patients suffering from cancer had not benefitted from improvements in cancer therapy to the same extent as children. ${ }^{[2]}$

Similar observations were made by NCI in 2006 in the AYA population when compared to children and older adults. Data showed that the patients belonging to the AYA subset reported little or no improvement in cancer survival. ${ }^{[3]}$ The shocking revelation was the low participation of these patients in clinical trials. They also enumerated in detail the further steps that need to be taken in the fields of epidemiology, disease biology, designing clinical trials, optimization of health services, and medical care. As the AYA population has great significance for all countries, special emphasis was also laid on the quality of life (QoL) of this population. ${ }^{[4]}$

AYA oncology represents $4.3 \%-6.2 \%$ of the total nations cancer burden. ${ }^{[5]}$ The GLOBOCAN 2018 suggests that the annual burden of cancer cases in India is over a million with approximately 55,000 patients in the AYA population and 30,286 deaths. ${ }^{[6,7]}$

AYA cancer patients have unique challenges to the oncology teams around the world. AYA diagnosis has been classified into three subgroups. The first subgroup (15-19 years) is an extension of pediatric tumors such as hematological and bone tumors. The second epoch includes patients from the age group of 20-24 years where testicular and thyroids are more common and leukemia persists. From 25 to 39 years, the trend toward breast and colon rise, although they are far aggressive as compared to their counterparts in the elderly population. ${ }^{[5]}$

When comparing the 5-year relative survival rates (1975-2014), there was an improvement of 20\% in older adults, $25 \%$ in children, and $15 \%$ in the AYA population. However, the above numbers when reviewed should be taken with caution due to various reasons. First, there were a higher proportion of less aggressive malignancies with a high 5 -year survival rates and thereby advancement in cancer therapy has led to lesser further benefit. Second, the lack of participation in clinical trials in this age group only complicates things. ${ }^{[8-13]}$

The reason for abandonment needs a special mention here as up to $38 \%$ of patients abandon their treatment due to various reasons, the highest being for hematological malignancies $(28 \%))^{[14]}$

Studies have focused on the reason for poor outcomes in this subset. These include differences in host and tumor biology, delayed diagnosis, lack of proper and specific guidelines leading to variation in treatment strategies, and poor compliance and adherence due to family and economic issues. ${ }^{[3,15]}$

The NCCN has issued detailed guidelines for discussing the various issues such as: ${ }^{[16]}$

- Fertility preservation and contraception before starting anticancer therapy

- Financial issues

- QoL-addressing issues such as infections, pain, emesis, cachexia, cosmesis, cognition, emesis, hair loss, nutrition, weight loss, and myelosuppression which are unique to each modality and approach

- Survivorship

- Screening

- Late effects of each modality, including vital organ damage and secondary malignancies

- End-of-life care.

So, how are these issues relevant to a resource-starved country like ours?

As compared to the West, we have different challenges. We do not have enough data on disease burden, resources are not plentiful, the difference in biology (both tumor and host), and socioeconomic considerations.

India is at a demographic divide. The so-called "lost tribe" of oncology in India forming a major percentage of the Indian population even if it contributes to a small percentage, the numbers will be massive. With limited resources, there is bound to be disruption of physical and psychosocial fiber.

As compared to US databases, studies done in India have shown a marked difference in the malignancy . profile in India. Arora et al..$^{[17]}$ and Kalyani et al..$^{[18]}$ both based on population based cancer registries, have documented these differences.

The most common sites of malignancies in India include head and neck squamous cell carcinoma, breast, cervix, gastrointestinal carcinomas, lung, and hematolymphoid malignancies. Modifiable or partly modifiable factors such as alcohol, tobacco, and lower SES play a major role in these malignancies along with lax government policies. Hence, early intervention can be offered and lives at stake can be saved. The lack of centralized insurance alienates the family in society and also affects the other family members. ${ }^{[6,7,17,18]}$ 
Improving the outcomes in this subset of the population is a daunting task. There needs to be a holistic approach.

First, improvement in clinical trial enrolment as per the progress review group recommendation ${ }^{[19]}$ is required. The enrolment of AYA patients in 2006 stood at a mere 14\%. ${ }^{[20]}$ Lack of insurance, poor representation of the older AYA population, and lack of pediatric centers were resulting in such a dismal situation. ${ }^{[21,22]}$ This population must be treated by pediatric oncologists as this subgroup does better when pediatric protocols are followed.

Second, the lack of health insurance is a big hindrance for these patients to undergo treatment for their generally aggressive diseases. Studies have shown that the majority of the Indian population does not have insurance coverage. Only a minority of these patients can afford the highly expensive cancer and supportive care. The state-sponsored hospitals which are often the less preferred options are overburdened, and with the one of the lowest percentage of GDP allocated to the health sector, the government-funded schemes fall short for appropriate treatment.

Third, interrupted social skills, educational and employment delays, psychosexual, and fertility issues result in delaying fiscal and emotional independence.

To conclude, AYA oncology is uncharted territory. In developing countries, good retrospective data to define the burden of disease are missing. The world is moving on toward prospective studies on this subset of cancer patients and we must do the same.

\section{Financial support and sponsorship}

Nil.

\section{Conflicts of interest}

There are no conflicts of interest.

\section{Sahil Gupta1, Esha Jafa², Akanksha Bansal ${ }^{3}$}

${ }^{\prime}$ Department of Medical Oncology, MS Ramaiah Medical College, Bengaluru, Karnataka, India, 'Department of Medical Oncology, SSCIH, Lucknow, Uttar Pradesh, India, ${ }^{3}$ Department of Pain and Palliation, Cytecare Cancer Hospital, Bengaluru, Karnataka, India

Address for correspondence: Dr. Sahil Gupta, MS Ramaiah Medical College, Bengaluru, Karnataka, India. E-mail:dr.sahil1986@gmail.com

Submitted: 23-Apr-2020

Revised: 01-Jun-2020

Accepted: 04-Aug-2020

Published: 29-Oct-2020

\section{References}

1. National Youth Policy-2014 Document (1730861). Available from: https://yas.nic.in/national-youth-policy. [Last accessed on 2019 May 04].
2. Bleyer WA. The adolescent gap in cancer treatment. J Registry Manag 1996;23:114-5.

3. Adolescent and Young Adult Oncology Progress Review Group. Closing the Gap: Research and Care Imperatives for Adolescent and Young Adults with Cancer. Available from: https://www. cancer.gov/types/aya/research/ayao-august-2006.pdf. [Last accessed on 2020 Mar 25].

4. Bleyer A, Tai E, Siegel S. Role of clinical trials in survival progress of American adolescents and young adults with cancer-and lack thereof. Pediatr Blood Cancer 2018;65:e27074.

5. Citalkar CP. Teenage and young adult cancer. A low hanging fruit or the final frontier? Indian J Med Peadiatr Oncol 2019;40:163-4.

6. GLOBOCAN 2018. Available from: http://gco.iarc.fr. [Last accessed on 2019 May 03].

7. Singh R, Shirali R, Chatterjee S, Adhana A, Arora RS. Epidemiology of cancers among adolescents and young adults from a tertiary cancer center in Delhi. Indian J Med Paediatr Oncol 2016;37:90-4.

8. Gupta N, Chitalkar P, Mishra R, Punia A. Epidemiology of cancer in young in central India: An analysis of rural cancer hospital data. South Asian J Cancer 2017;6:183-5.

9. Stock W, Luger SM, Advani AS, Yin J, Harvey RC, Mullighan CG, et al. A pediatric regimen for older adolescents and young adults with acute lymphoblastic leukemia: Results of CALGB 10403. Blood 2019;133:1548-59. doi: 10.1182/ blood-2018-10-881961. Epub 2019 Jan 18. Erratum in: Blood. 2019 Sep 26;134(13):1111. PMID: 30658992; PMCID: PMC6450431.

10. Hochberg J, Flower A, Brugieres L, Cairo MS. NHL in adolescents and young adults: A unique population. Pediatr Blood Cancer. 2018 Aug;65(8):e27073. doi: 10.1002/pbc.27073. Epub 2018 May 9. PMID: 29741220.

11. Reed DR, Naghavi A, Binitie O. Sarcoma as a model for adolescent and young adult care. J Oncol Pract 2019;15:239-47.

12. Johnson RH, Anders CK, Litton JK, Ruddy KJ, Bleyer A. Breast cancer in adolescents and young adults. Pediatr Blood Cancer. 2018;65:e27397. doi: 10.1002/pbc.27397. Epub 2018 Aug 28. PMID: 30156052; PMCID: PMC6192832.

13. Tricoli JV, Boardman LA, Patidar R, Sindiri S, Jang JS, Walsh WD, et al. A mutational comparison of adult and adolescent and young adult (AYA) colon cancer. Cancer. 2018 1;124:1070-82. doi: 10.1002/cncr.31136. Epub 2017 Nov 30. PMID: 29194591; PMCID: PMC5821537.

14. Chitalkar Prakash G, Taran R, Kumbhaj P, Singla, D. Incidence and treatment abandonment in teen and young adult cancer. Nat J Med Res 2016;6:77-9.

15. Coccia PF. Don't give up - They eventually grow up: Issues in AYA medicine. J Natl Compr Canc Netw 2012;10:1059-60.

16. National Comprehensive Cancer Network: Clinical Practice Guidelines in Oncology: Adolescent and Young Adult (AYA) Oncology, Version 1; 2019. Available from: http://www. NCCN. org. [Last accessed on 2020 Mar 25].

17. Arora RS, Alston RD, Eden TO, Moran A, Geraci M, O'Hara C, et al. Cancer at ages 15-29 years: The contrasting incidence in India and England. Pediatr Blood Cancer 2012;58:55-60.

18. Kalyani R, Das S, Kumar ML. Pattern of cancer in adolescent and young adults- A ten year study in India. Asian Pac J Cancer Prev 2010;11:655-9. 
19. Adolescent and Young Adult Oncology Group. Closing the Gap: Research and Care Imperatives for Adolescents and Young Adults with Cancer. Available from: deainfo.nci.nih.gov/ advisory/ncab/archive/139_0906/presentations/AYAO.pdf. [Last accessed on 2019 Jan 21].

20. Parsons HM, Harlan LC, Seibel NL, Stevens JL, Keegan TH. Clinical trial participation and time to treatment among adolescents and young adults with cancer: Does age at diagnosis or insurance make a difference? J Clin Oncol 2011;29:4045-53.

21. Jacob SA, Shaw PH. No improvement in clinical trial enrollment for adolescents and young adults with cancer at a children's hospital. Pediatr Blood Cancer 2017;64:e26638.

22. Roth ME, O'Mara AM, Seibel NL, Dickens DS, Langevin AM, Pollock BH, et al. Low enrollment of adolescents and young adults onto cancer trials: Insights from the Community Clinical Oncology Program. J Oncol Pract 2016;12:e388-95.
This is an open access journal, and articles are distributed under the terms of the Creative Commons Attribution-NonCommercial-ShareAlike 4.0 License, which allows others to remix, tweak, and build upon the work non-commercially, as long as appropriate credit is given and the new creations are licensed under the identical terms.

\begin{tabular}{|l|l|}
\hline \multicolumn{2}{|c|}{ Access this article online } \\
\hline Quick Response Code: & Website: \\
& www.ijmpo.org \\
\cline { 2 - 2 } & Dol: \\
\hline
\end{tabular}

How to cite this article: Gupta S, Jafa E, Bansal A. Issues in adolescent and young adult oncology in a developing country like India. Indian J Med Paediatr Oncol 2020;41:724-6. 